\title{
Investigation of Compact Balun-Bandpass Filter Using Folded Open-Loop Ring Resonators and Microstrip Lines
}

\author{
Chia-Mao Chen, ${ }^{1}$ Shoou-Jinn Chang, ${ }^{2}$ Sung-Mao Wu, ${ }^{3}$ \\ Yuan-Tai Hsieh, ${ }^{4}$ and Cheng-Fu Yang ${ }^{5}$ \\ ${ }^{1}$ Institute of Microelectronics and Department of Electrical Engineering, National Cheng Kung University, Tainan 701, Taiwan \\ ${ }^{2}$ Institute of Microelectronics and Department of Electrical Engineering, Center for Micro/Nano Science and Technology, \\ Advanced Optoelectronic Technology Center, National Cheng Kung University, Tainan 701, Taiwan \\ ${ }^{3}$ Department of Electrical Engineering, National University of Kaohsiung, Kaohsiung 811, Taiwan \\ ${ }^{4}$ Department of Electronic Engineering, Southern Taiwan University, Tainan 710, Taiwan \\ ${ }^{5}$ Department of Chemical and Materials Engineering, National University of Kaohsiung, Kaohsiung 811, Taiwan
}

Correspondence should be addressed to Cheng-Fu Yang; cfyang@nuk.edu.tw

Received 2 May 2014; Accepted 7 June 2014; Published 1 July 2014

Academic Editor: Teen-Hang Meen

Copyright (C) 2014 Chia-Mao Chen et al. This is an open access article distributed under the Creative Commons Attribution License, which permits unrestricted use, distribution, and reproduction in any medium, provided the original work is properly cited.

\begin{abstract}
A balun-bandpass filter was proposed by using two folded open-loop ring resonators (OLRRs) to couple three microstrip lines. By tuning the size of the OLRR, the operating frequency of the balun-bandpass filter could be tuned to the needed value. By tuning the size of open stub at the end of microstrip lines, the balanced impedance of the balun-bandpass filter could also be tuned. The fabricated balun-bandpass filter had a wide bandwidth and a low insertion loss at center frequency of the passband. The balunbandpass filter presented an excellent in-band balanced performance with common-mode rejection ratio more than $20 \mathrm{~dB}$ in the passbands. An advanced design methodology had been adopted based on EM simulation for making these designed parameters of OLRRs and microstrip lines. Good correlation was seen between simulation and measurement, and the result was that first run pass had been achieved in the majority of our designs.
\end{abstract}

\section{Introduction}

A mass of RF/microwave modules is designed for portable terminals such as handsets, e-readers, and tablet PCs. Integration of two functional blocks in a single circuit is the most intuitive way to reduce the cost as well as the circuit size. Bandpass filters (BPFs) and baluns are critical components in the RF channels because most of the RF-front end modules require bandpass filters and baluns. Some balun BPFs are evolved from the classic quarter- and half-wavelength resonators with folding topology [1]. To cater for dual-band wireless systems, plenty of researches focus on the balun BPFs with two passbands [2]. In [3, 4], single dual-mode resonators are employed to construct a compact balun BPF. To extend the ability of the microwave components to support multiple frequency bands, tunable or reconfigurable techniques have drawn much attention for researches and developments. To achieve the requirement of the compact and low-cost RF module for the modern wireless communication system, the balun BPFs with the balance-to-unbalance conversion are highly desired. Accordingly, all kinds of tunable BPFs have been under intensive developments [5], but relatively only few researches have been done on the tunable balun BPFs [6].

In the present study, a generalized methodology for designing a novel and simple single passband balun BPF was investigated. The low-loss balun BPF was using two folded open-loop ring resonators (OLRRs) with equal physical dimensions to couple three microstrip lines, as Figure 1 shows. Each OLRR is placed between two microstrip lines and has a perimeter of about a half wavelength of the designed resonant frequency. Each of the fold OLRRs has its maximum electric field density near the open ends of the line and has its maximum magnetic field density around the center valley of the microstrip line. The resonant frequencies can 


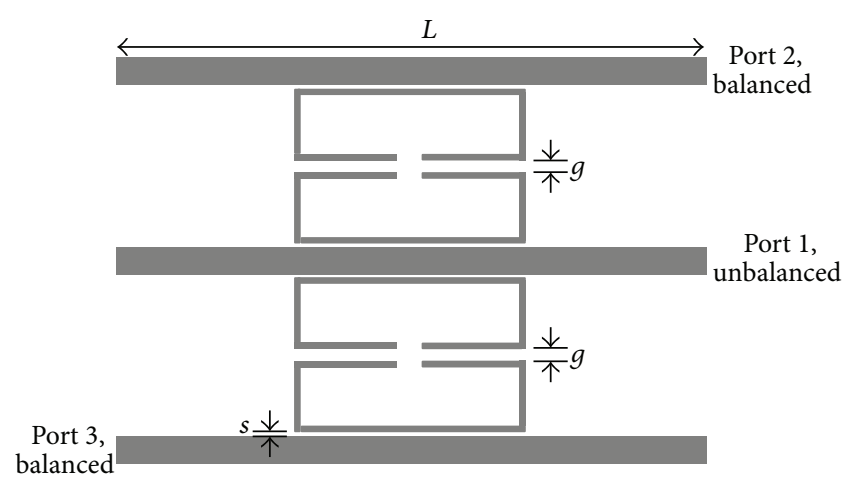

FIgURE 1: Proposed balun-bandpass filter (BPF) based on OLRRs.

be adjusted via the length of the OLRRs to provide a highperformance passband response. The proposed balun BPF has low insertion loss, a wide tunable range of passband, transmission zeros, and simple design. By tuning the size of open stub at the end of microstrip line, the balanced impedance of the balun BPF can be tuned. Finally, we fabricated a high-performance balun BPF on FR4 substrates to demonstrate the proposed structure.

\section{Design Methodology}

To obtain the maximum magnetic coupling, the center valley of the OLRRs must be positioned in the proper location along the microstrip line with the maximum magnetic field intensity, which can be determined by studying wave motions on a microstrip line. For the transverse electromagnetic (TEM) field structure, both the electric and magnetic field vectors lie in the transverse plane, which is perpendicular to the uniform propagation axis. Under the assumptions of the TEM mode of propagation and a lossless line, the fields $\vec{E}$ and $\vec{H}$ are uniquely related to voltage and current, respectively. Based on transmission line theory, the magnitudes of voltage and current on the microstrip line can be expressed in terms of the incident wave and the reflection coefficient:

$$
\begin{aligned}
& |V(z)|=\left|V_{0}^{+}\right||1+| \Gamma\left|e^{j(\theta-2 \beta l)}\right| \\
& |I(z)|=\frac{\left|V_{0}^{+}\right|}{Z_{0}}|1-| \Gamma\left|e^{j(\theta-2 \beta l)}\right|,
\end{aligned}
$$

where $l=-z$ is measured away from the load at $z=0$ and $\theta$ is the phase of the reflection coefficient. When $\theta-2 \beta d$ has a magnitude of zero or any multiple of $2 \pi$ radian, voltage in (1) is at its maximum magnitude and current in (2) is at its minimum magnitude, respectively. For the case of an opencircuited line, (1) and (2), respectively, become

$$
\begin{aligned}
& |V(z)|=\left|V_{0}^{+}\right|\left|1+e^{j(\theta-2 \beta l)}\right| \\
& |I(z)|=\frac{\left|V_{0}^{+}\right|}{Z_{0}}\left|1-e^{j(\theta-2 \beta l)}\right| .
\end{aligned}
$$

At a distance of a quarter wavelength from the receiving end, the voltage becomes zero while the current is at its

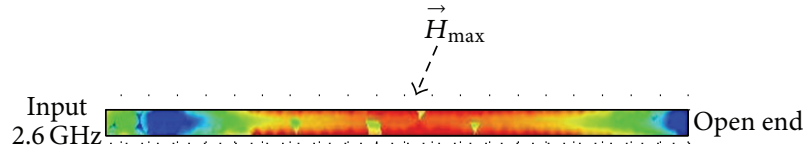

FIGURE 2: Current distribution in microstrip line terminated at open end.

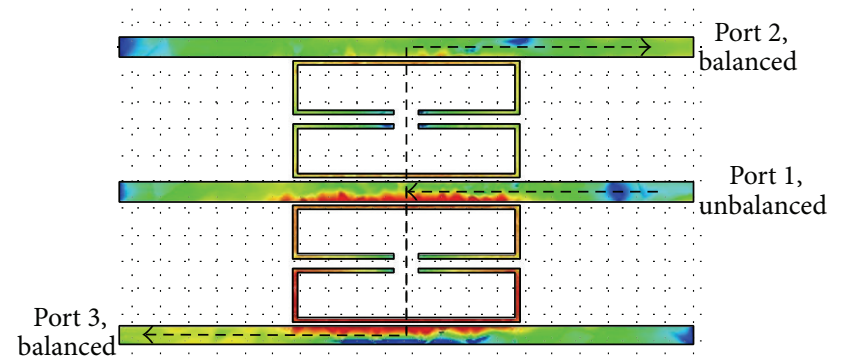

FIgURE 3: Simulation of current distribution and coupling paths oscillating at $2.6 \mathrm{GHz}$.

maximum. If the line has a value of half wavelength, the current distribution near the center of the transmission line is at its maximum. High magnetic coupling results from a high conduction current. Once the point of $I_{\max }$ is found, the point of $H_{\max }$ can be easily determined. Figure 2 shows a uniform section of a transmission line of length $L$, where $L$ is about $0.5 \lambda$ under operation frequency of $2.6 \mathrm{GHz}$. This result suggests that the resonant frequency of the designed balun BPFs can be adjusted by changing the dimension of the OLRRs.

To demonstrate that the proposed structure is available, balun BPF is designed using OLRRs to couple microstrip transmission lines. To excite the passbands, two pairs of guided half-wavelength OLRRs should be located between two microstrip lines, and the microstrip lines are terminated with open ends. Each OLRR provides a path coupled signal energy from one microstrip line to another at around resonance frequency. When the signal is above and below resonance frequency, most of the energy is reflected back and the standing waves are said to exist on the line, as Figure 3 shows. After the designed balun BPFs are simulated using the HFSS simulator with loss factors (conductor loss and dielectric loss) included in the simulated response to find the optimal parameters, the coupling paths shown in Figure 3 are chosen specifically for resonant frequency.

Besides having good match in input impedance and good amplitude and phase balances between the two output ports, the match in output balanced impedance will make balun BPFs have more attraction in the sense of the system integration ability. This structure is very easy for designer to tune balanced impedance, because we only need to adjust the width $\left(W_{B}\right)$ of balanced-port microstrip line and add openstub line, as the structure shown in Figure 4. 


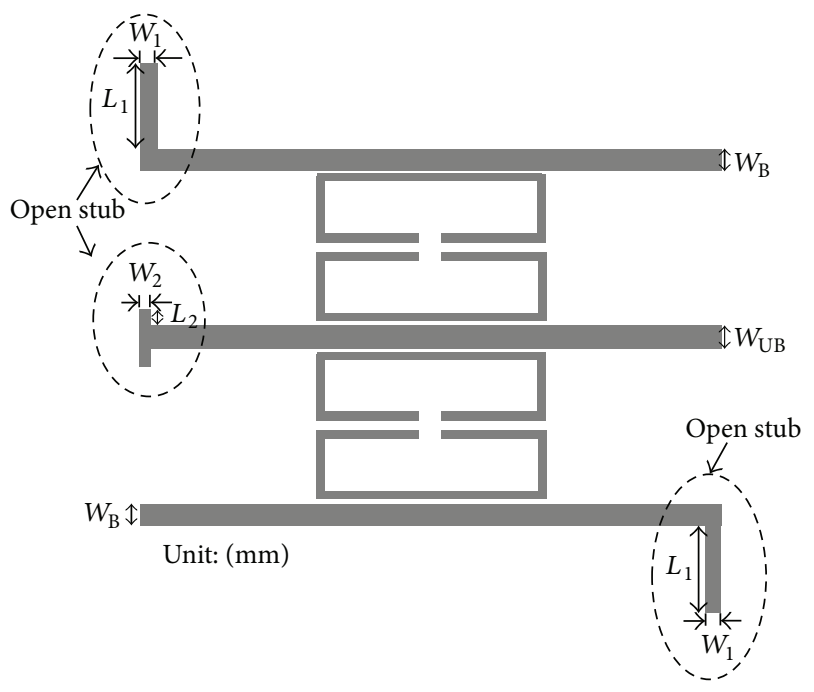

Figure 4: Balun BPF with open stub.

To characterize the balance characteristic of the balun BPFs, the mode conversion between the unbalanced threeport network and the unbalanced-to-balanced two-port network is applied to obtain the single-ended to differentialmode and common-mode parameters $[7,8]$ :

$$
\begin{gathered}
S_{s s 11}=S_{11} \\
S_{d s 21}=\frac{\left(S_{21}-S_{31}\right)}{\sqrt{2}} \\
S_{c s 21}=\frac{\left(S_{21}-S_{31}\right)}{\sqrt{2}}
\end{gathered}
$$

where $S_{d s 21}$ and $S_{c s 21}$ are the couplings of mixed-mode parameters, $S_{d s 21}$ is from the unbalanced input port 1 to the differential-mode output port 2, and $S_{c s 21}$ is from the unbalanced input port 1 to the common-mode output port 2 , respectively.

\section{Design of Balun-Bandpass Filters}

The simulated frequency response of the $2.6 \mathrm{GHz}$-based balun BPF with better design parameters is shown in Figure 5 with layout pattern shown in the inset. The designed balun BPF is based on two pairs of half-wavelength OLRRs. Electric coupling can be obtained if the open sides of the two coupled resonators are placed near each other, and magnetic coupling can be obtained if the sides with the maximum magnetic field of two coupled resonators are placed near each other. The coupling spacing $s$ between the main microstrip line and OLRRs is $0.2 \mathrm{~mm}$ and the spacing $g$ between two resonators is $0.61 \mathrm{~mm}$. The center frequency of the designed balun BPF can be accurately controlled to a desired band once the correct position is chosen. The balanced impedance is about $(78+$ j18) $\mathrm{Ohm}$ at $2.6 \mathrm{GHz}$. The simulation result of the designed balun BPF shows good match in input impedance, good amplitude and phase balances between the two output ports, and a wide passband. Those simulated results prove that we
TABLE 1: Balanced impedance of the balun BPFs with open stub.

\begin{tabular}{lcccccc}
\hline$W_{\mathrm{UB}}$ & $W_{B}$ & $W_{1}$ & $L_{1}$ & $W_{2}$ & $L_{2}$ & Balanced impedance, $\Omega$ \\
\hline 1.5 & 1.5 & 0 & 0 & 0 & 0 & $78+j 18$ \\
1.5 & 1.125 & 0 & 0 & 0.75 & 2 & 100 \\
1.5 & 1.5 & 0.95 & 5 & 0.75 & 1 & 50 \\
\hline
\end{tabular}

only need to find the optimum width $\left(W_{B}\right)$ of balanced-port microstrip line and add open-stub line and then we can tune balanced impedance; the balanced impedance of the balun BPFs with open stub is shown in Table 1 .

Both patterns in Figures 6 and 7 have the same designed structures. In order to design the balanced impedance that is needed, the sizes of open stub and $W_{B}$ are different from each other. The balun BPF using OLRRs was fabricated on an FR4 substrate with a relative permittivity of 4.4 and thickness between the two electrodes was $1.2 \mathrm{~mm}$. The dimension for the proposed balun BPF with balanced impedance of $100 \mathrm{Ohm}$ is $41 \mathrm{~mm} \times 22.21 \mathrm{~mm}$, as shown in Figure 6(a), and the photograph of the fabricated balun BPF is shown in Figure 6(b). Similarly, the dimension for the proposed balun BPF with balanced impedance of $50 \mathrm{Ohm}$ is about $41 \mathrm{~mm} \times$ $32.96 \mathrm{~mm}$, as shown in Figure 7(a), and the photograph of the fabricated balun BPF is shown in Figure 7(b). Measurements were carried out using an Agilent N5071C network analyzer. Figures 8(a) and 8(b) show the full-wave simulated and measured results of the $S$-parameters and phase/amplitude differences for the circuit with balanced impedance of 100 Ohm; Figures 9(a) and 9(b) show those for the circuit with balanced impedance of $50 \mathrm{Ohm}$, respectively. The measured $S_{d s 21}$ values at the center frequencies of each passband in Figures $8(\mathrm{a})$ and $9(\mathrm{a})$ are 1.98 and $2.19 \mathrm{~dB}$, respectively. The measured $3 \mathrm{~dB}$ band-edge frequencies of $S_{d s 21}$ values are observed at $f_{L, 100 \Omega}=2.43 \mathrm{GHz}$ and $f_{H, 100 \Omega}=2.88 \mathrm{GHz}$ for Figure $8(\mathrm{a})$ and at $f_{L, 50 \Omega}=2.49 \mathrm{GHz}$ and $f_{H, 50 \Omega}=2.77 \mathrm{GHz}$ for Figure 9(a), respectively. The simulated and measured $S_{c s 21}$ values are smaller than $20 \mathrm{~dB}$ within operating bands of two balun BPFs, which demonstrates good common-mode suppression at the differential output port. Figures 8(a) and 9(a) also show that the amplitude difference between $S_{21}$ and $S_{31}$ is below $2 \mathrm{~dB}$ and the phase difference between $S_{21}$ and $S_{31}$ is within $180 \pm 10^{\circ}$ at each operating band. The proposed balun BPFs present a wide bandwidth, because they have two resonant frequencies within the passband. The balance impedance will affect the electrical performance of return loss, as shown in Figures 8(a) and 9(a); for that there is one peak or two peaks. The little difference between the simulated and measured results is mainly caused by the fabrication error (circuit etching), the SMA connector, and numerical error.

\section{Conclusions}

We presented a simple and effective method for designing a microstrip balun BPF with differential outputs. By adjusting the physical dimensions of the OLRRs, the center frequencies of the balun BPF could be tuned over a wide range. The balanced impedance was tuned easily by open stub and $W_{B}$. The balun-bandpass filter not only possessed good bandpass 


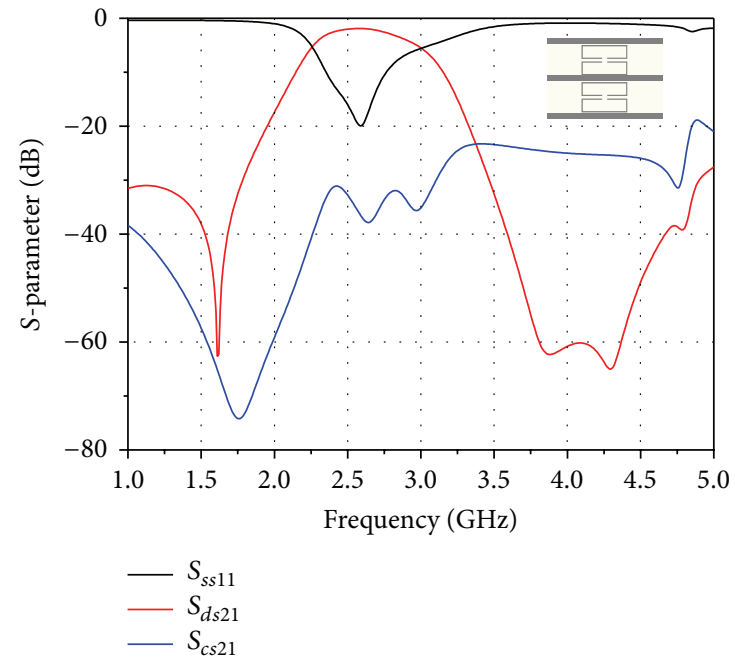

(a)

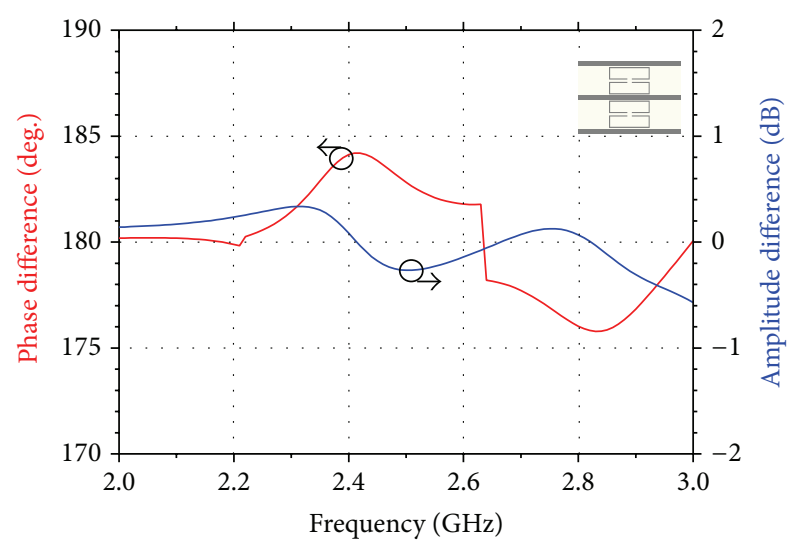

(b)

FIGURE 5: Simulated results of the designed balun BPF (a) S-parameters and (b) magnitude and phase differences.

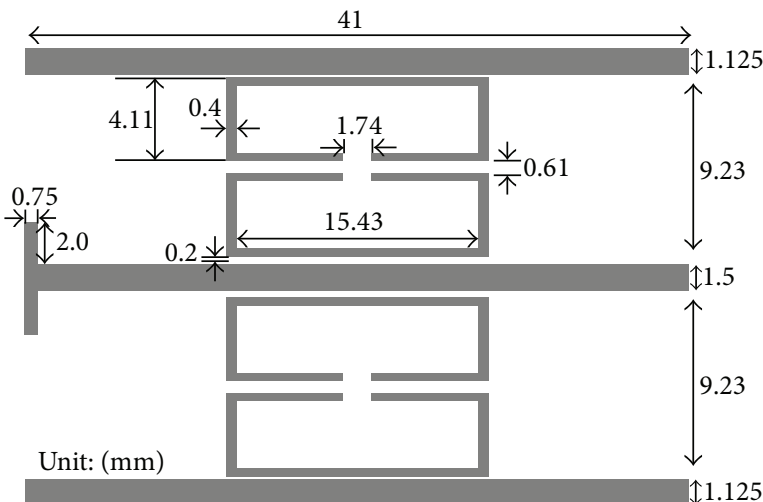

(a)

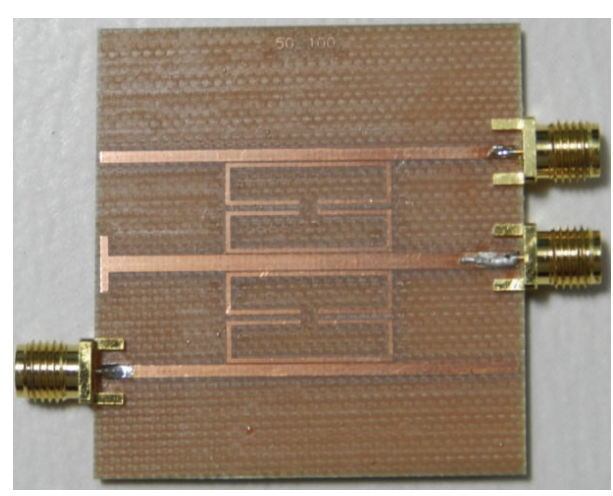

(b)

FIGURE 6: (a) Layout pattern and (b) photograph of the designed balun BPF with about 100- $\Omega$ balanced impedance.

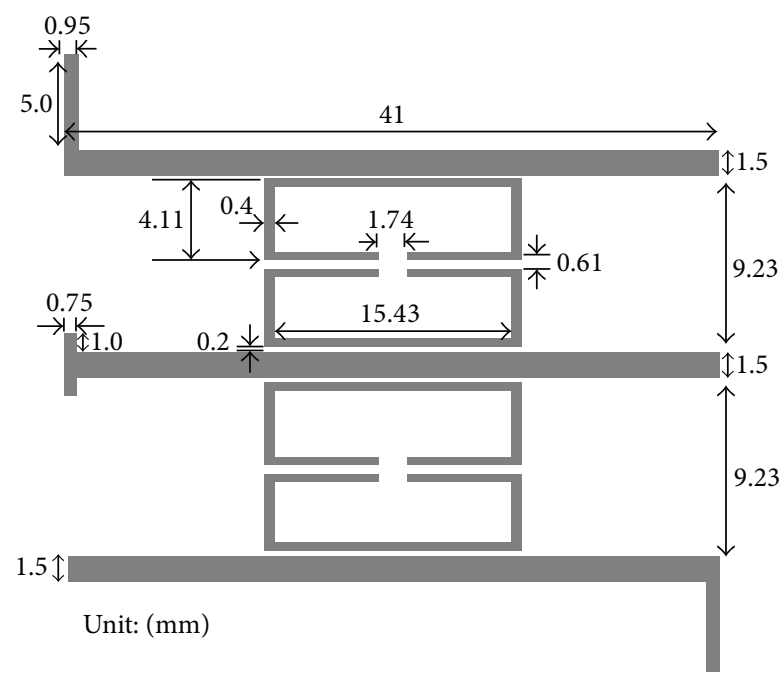

(a)

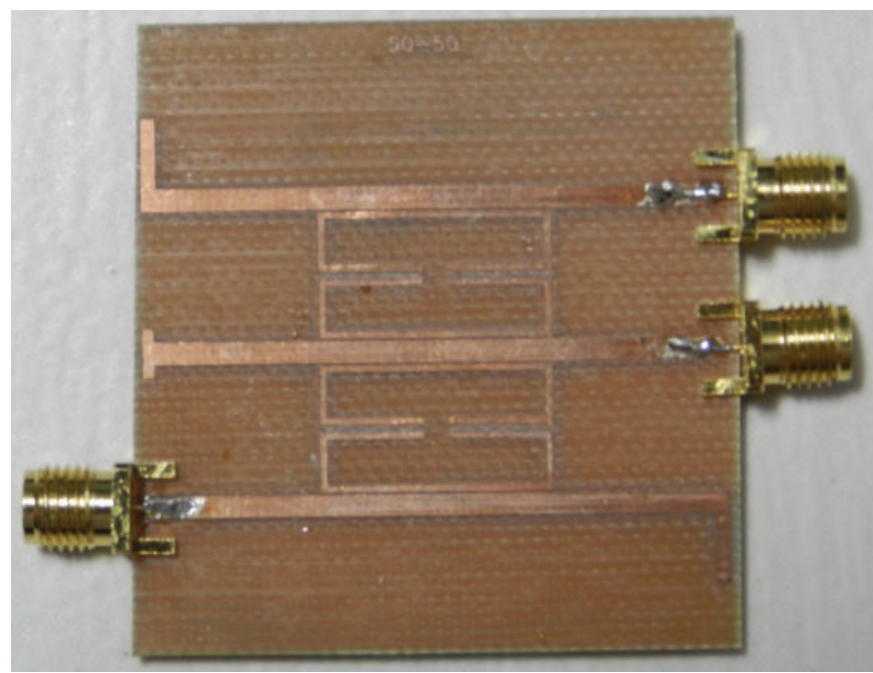

(b)

FIGURE 7: (a) Layout pattern and (b) photograph of the designed balun BPF with about $50-\Omega$ balanced impedance. 


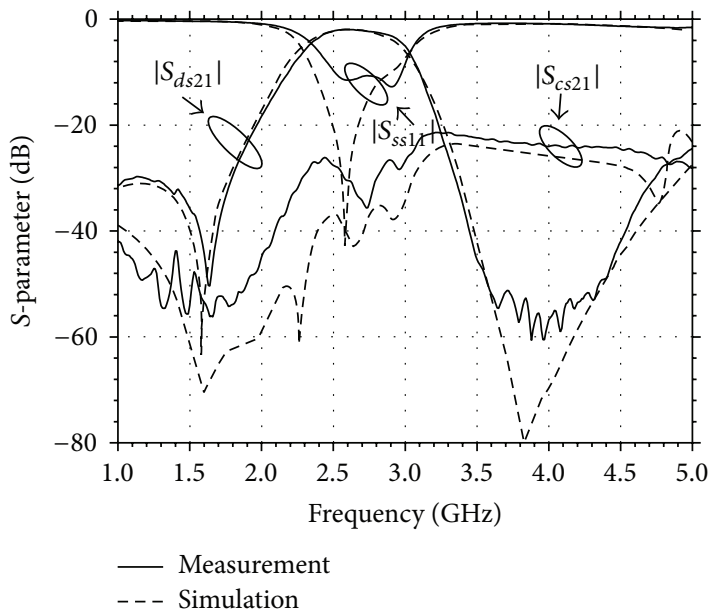

(a)

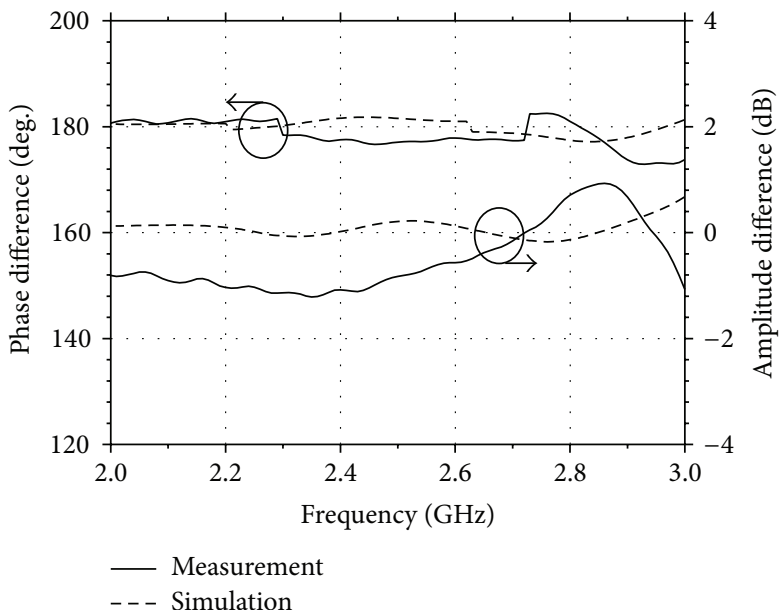

(b)

FIGURE 8: (a) S-parameters and (b) phase/amplitude difference of the designed balun BPF with about 100- $\Omega$ balanced impedance.

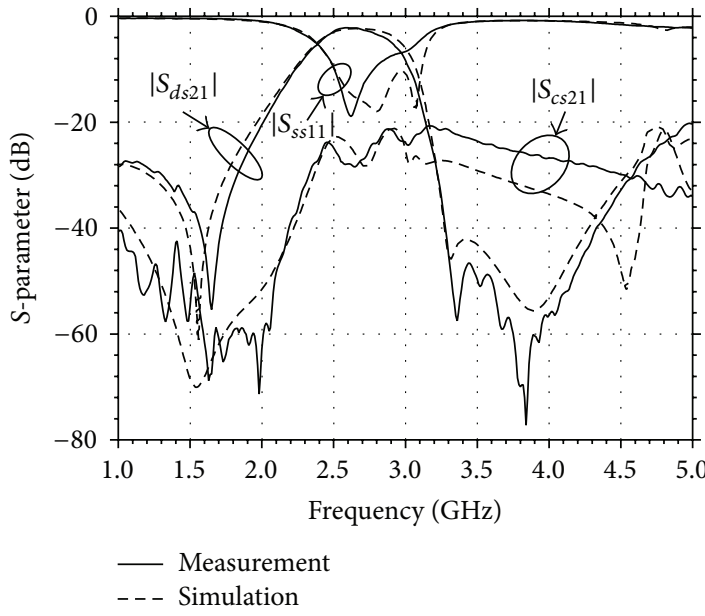

(a)

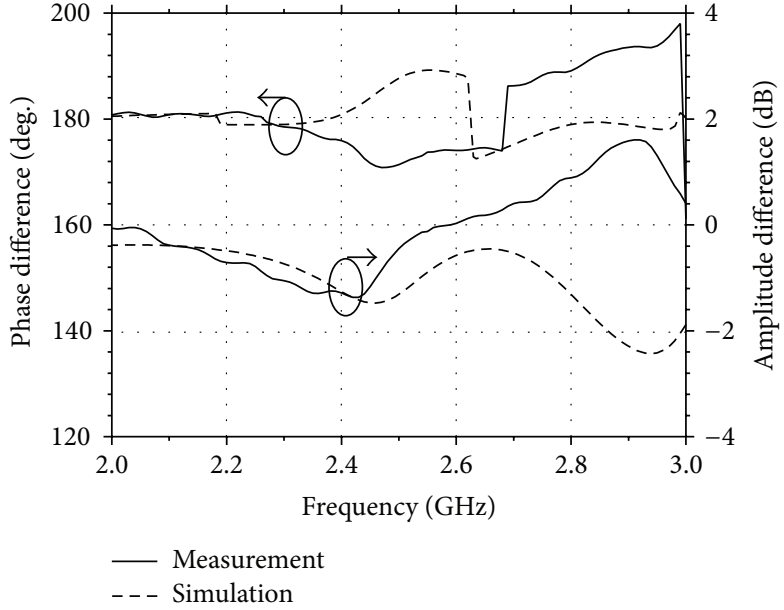

(b)

FIgURE 9: (a) $S$-parameters and (b) phase/amplitude difference of the designed balun BPF with about 50- $\Omega$ balanced impedance.

characteristics, as the results shown in Figures 8 and 9, the two balun BPFs had the good performance. A prototype was designed and fabricated, with the measured results given.

\section{Conflict of Interests}

The authors declare that they have no conflict of interests regarding the publication of this paper.

\section{Acknowledgment}

The authors acknowledge financial supports of NSC 1022622-E-390-002-CC3, NSC 102-2221-E-390-027, and NSC 102-2221-E-218-036.

\section{References}

[1] L. K. Yeung and K. L. Wu, "A dual-band coupled-line balun filter," IEEE Transactions on Microwave Theory and Techniques, vol. 55, no. 11, pp. 2406-2411, 2007.

[2] G. S. Huang and C. H. Chen, "Dual-band balun bandpass filter with hybrid structure," IEEE Microwave and Wireless Components Letters, vol. 21, no. 7, pp. 356-358, 2011.

[3] E. Y. Jung and H. Y. Hwang, "A balun-BPF using a dual mode ring resonator," IEEE Microwave and Wireless Components Letters, vol. 17, no. 9, pp. 652-654, 2007.

[4] L.-H. Zhou, H. Tang, J.-X. Chen, and Z.-H. Bao, "Tunable filtering balun with enhanced stopband rejection," EEE Electronics Letters, vol. 48, no. 14, pp. 845-847, 2012. 
[5] J. S. Sun, N. Kaneda, Y. Baeyens, T. Itoh, and Y. K. Chen, "Multilayer planar tunable filter with very wide tuning bandwidth," IEEE Transactions on Microwave Theory and Techniques, vol. 59, no. 11, pp. 2864-2871, 2011.

[6] X. Miao, W. Zhang, Y. Geng, X. Chen, R. Ma, and J. Gao, "Design of compact frequency-tuned microstrip balun," IEEE Antennas and Wireless Propagation Letters, vol. 9, pp. 686-688, 2010.

[7] Q. Xue, J. Shi, and J. X. Chen, "Unbalanced-to-balanced and balanced-to-unbalanced diplexer with high selectivity and common-mode suppression," IEEE Transactions on Microwave Theory and Techniques, vol. 59, no. 11, pp. 2848-2855, 2011.

[8] W. R. Eisenstadt, R. Stengel, and B. M. Thompson, Microwave Differential Circuit Design Using Mixed-Mode S-Parameters, Artech House, Boston, Mass, USA, 2006. 


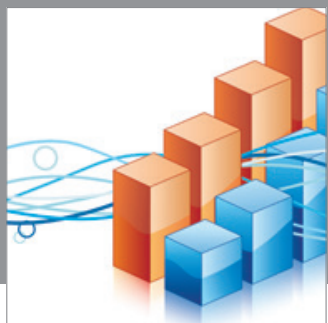

Advances in

Operations Research

mansans

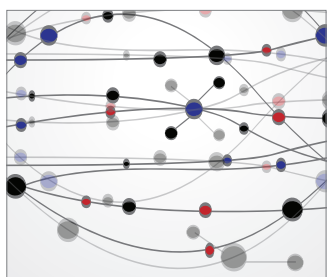

The Scientific World Journal
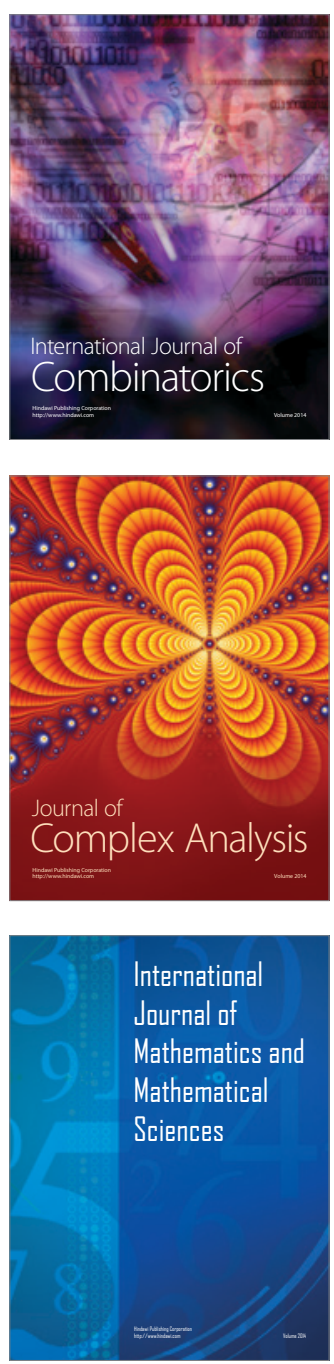
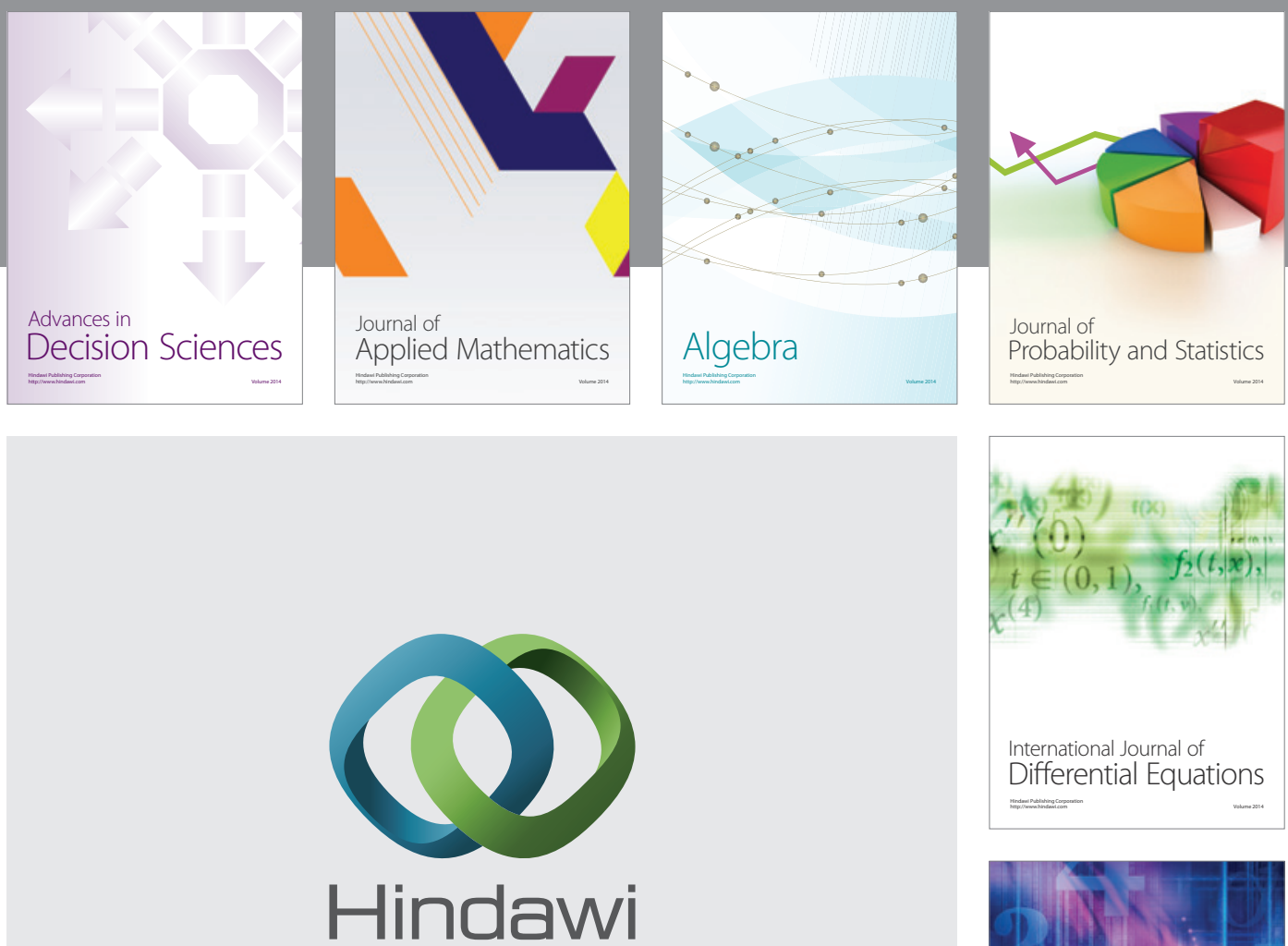

Submit your manuscripts at http://www.hindawi.com
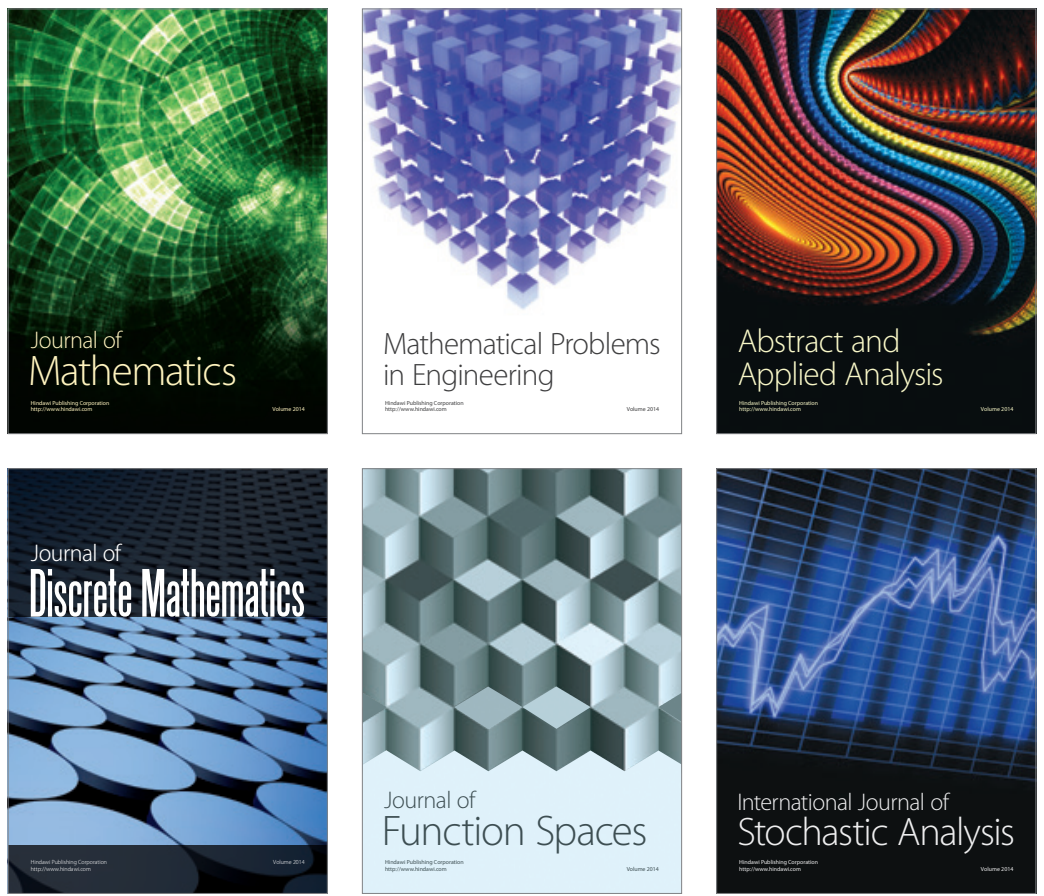

Journal of

Function Spaces

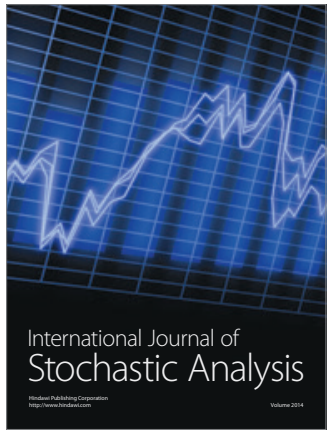

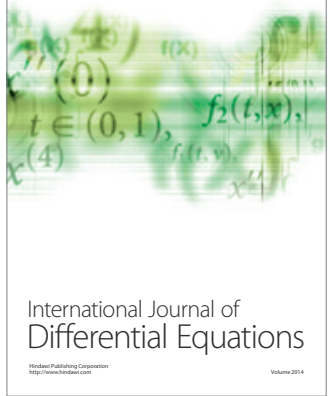
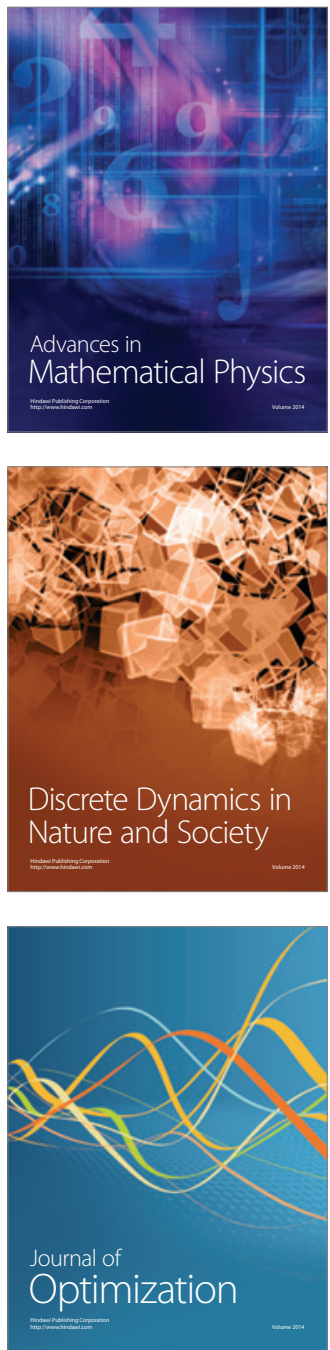